\title{
Mice with Chronically Elevated Dopamine Exhibit Enhanced Motivation, but not Learning, for a Food Reward
}

\author{
Barbara Cagniard ${ }^{*,}$, Peter D Balsam ${ }^{2,3}$, Daniela Brunner ${ }^{3,4}$ and Xiaoxi Zhuang' \\ 'Department of Neurobiology, Pharmacology and Physiology, The University of Chicago, Chicago, IL, USA; ${ }^{2}$ Department of Psychology, Barnard \\ College of Columbia University, New York, NY, USA; ${ }^{3}$ Department of Biopsychology, New York State Psychiatric Institute, New York, NY, USA; \\ ${ }^{4}$ PsychoGenics Inc., Hawthorne, NY, USA
}

\begin{abstract}
Dopamine has been critically implicated in learning and motivation, although its precise role remains to be determined. In order to investigate the involvement of dopamine in learning and motivation for a food reward, we used dopamine transporter knockdown mice (DAT KD) that have chronically elevated levels of extracellular dopamine. The present study demonstrates that chronically elevated dopamine enhances tendency to work for a food reward without apparent effects on Pavlovian and operant learning for this reward. The increase in dopamine is associated with elevated levels of dynorphin and Fos B expression in the dorsal caudate-putamen and the core but not the shell subregion of the nucleus accumbens. These data suggest that motivation to work, but not learning, for a food reward appears to be under the critical influence of tonic dopaminergic activity in discrete brain areas relevant for a reward-directed behavior. Neuropsychopharmacology (2006) 3 I, 1362-1370. doi:I 0. I038/sj.npp. I 300966; published online 23 November 2005
\end{abstract}

Keywords: dopamine transporter; knockdown; associative learning; motivation; striatum; mice

\section{INTRODUCTION}

Dopamine has been critically implicated in Pavlovian and instrumental learning invoked during acquisition of behaviors associated with a food-reward (Beninger and Miller, 1998; Di Chiara, 2002; Wise, 2004). Disruption of dopamine function by administration of dopamine receptor antagonists impairs acquisition of food conditioned place preference (Duarte et al, 2003; Spyraki et al, 1982), Pavlovian approach behavior (Di Ciano et al, 2001; Parkinson et al, 2002), and lever pressing for a food reward (Smith-Roe and Kelley, 2000; Wise and Schwartz, 1981). Moreover, it has been shown that dopamine neuron firing correlates with reward-related learning (Roitman et al, 2004; Schultz, 2002) perhaps by modulating synaptic plasticity (Calabresi et al, 1992; Centonze et al, 2001). However, despite the evidence linking dopamine function to learning, mice lacking the ability to synthesize dopamine were recently reported to be able to acquire an appetitive T-maze task (Robinson et al, 2005).

*Correspondence: Dr B Cagniard, Department of Neurobiology, Pharmacology and Physiology, The University of Chicago, 924E.57th Street, Room R222, Chicago, IL 60637, USA, Tel: + I 773834 9006, Fax: + I 773834 3808, E-mail: Barbara.cagniard@gmail.com

Received 20 July 2005; revised 6 October 2005; accepted 7 October 2005

Online publication: 13 October 2005 at http://www.acnp.org/citations/ Npp I01305050465/default.pdf
Dopamine has also been implicated in the expression and maintenance of food-directed behavior, that is, food motivation (Beninger and Miller, 1998; Di Chiara, 2002; Wise, 2004). Pharmacological and genetic blockade of dopamine receptors has been shown to reduce operant responding for food (Hoffman and Beninger, 1989; Nakajima, 1989), to disrupt instrumental responses in a sucrose-reinforced runway task (Ikemoto and Panksepp, 1996), and an appetitive T-maze task (Robinson et al, 2005). Interestingly, dopaminergic lesion of the nucleus accumbens reduced lever pressing for food under a high workload (fixed ratio (FR) 16 and FR64) but not under a low workload (FR1) condition (Aberman and Salamone, 1999; McCullough et al, 1993). Similarly, in a T-maze experiment, blockade of dopamine receptors or depletion of accumbens dopamine induced a shift from climbing a barrier to access an arm with high density of reward, to enter an unobstructed arm with a low density of reward (Cousins et al, 1996; Salamone et al, 1994). Symmetrically, systemic or intra-accumbens administration of amphetamine, which increases extracellular levels of dopamine has been reported to increase food motivated behavior under a progressive ratio (PR) schedule of reinforcement (Poncelet et al, 1983; Zhang et al, 2003). These findings suggest that dopamine functions to modulate an animal's tendency to work for a food reward (Salamone and Correa, 2002).

We have previously reported that DAT KD mice demonstrate greater performance for a sweet reward in a runway task (Pecina et al, 2003). These mice express only $10 \%$ of wild-type (WT) dopamine transporter levels and 
have chronically elevated level of extracellular dopamine in the striatum (Zhuang et al, 2001). Although the greater performance of DAT KD mice in the runway task may be due to an enhancement of motivation, a facilitation of associative learning could not be excluded as an alternative explanation. To further clarify the role of dopamine in foodrelated learning and motivation, in particular the tendency to work for a food reward, we compared the DAT KD mice and their WT littermate controls in their acquisition of appetitive Pavlovian and operant conditionings as well as in their performance on a PR schedule of reinforcement and on a concurrent choice task for a food reward. Furthermore, as chronic stimulation of the dopaminergic system induces FosB, dynorphin, and enkephalin expressions (Cole et al, 1995; Gerfen, 1992; Nestler et al, 1999), we evaluated the consequence of chronically elevated levels of extracellular dopamine on FosB, dynorphin, and enkephalin expression in the striatum of DAT KD mice.

\section{MATERIALS AND METHODS}

\section{Subjects}

The generation of the DAT KD mice has been previously described (Zhuang et al, 2001). Male DAT KD mice and their WT littermate controls were generated at the University of Chicago by heterozygote breeding. All mice were on a $129 \mathrm{~Sv} / \mathrm{J}$ genetic background. All experiments were carried out during the light period (0600-1800). During behavioral testing, body weights were maintained at desired food deprivation level by adjusting the amount of food given every day according to individual body weights. Water was available ad libitum. All animal procedures were approved by the Institutional Animal Care and Use Committee at the University of Chicago and at the New York State Psychiatric Institute.

\section{Behavioral Tests}

Pavlovian associative learning. Mice ( $n=8$ per genotype) were habituated to the conditioning chambers (Coulbourn Instruments) by placing them in the experimental enclosure for $15 \mathrm{~min}$ on 2 consecutive days. During these sessions, four food pellets were placed in the feeder. All animals ate the pellets by the end of the second session. Mice were then trained for 9 days with 20 daily trials (180 s variable intertrial interval). Each trial consisted of a 12-s illumination of a feeder light followed by a single $20 \mathrm{mg}$ food pellet. Interruptions of a feeder photobeam indicated magazine entries.

Acquisition of instrumental responding. The $\mathrm{PR}$ and the concurrent choice tasks were conducted in operant conditioning chambers (Med Associates Inc.). Mice $(n=9$ per genotype) were first trained under a FR1 schedule with only the active lever (right lever) extended. A session lasted 45 min or until a subject earned 50 pellets. During the first 2 days of training, food pellets (20-mg chocolate flavored pellets, Bio-Serv) were also delivered into the food receptacle on a variable time $60 \mathrm{~s}$ schedule with intervals ranging between 0 and $120 \mathrm{~s}$. When mice reached a criterion of 50 lever presses on 2 consecutive days, they were trained with two additional days of FR1 training with the left lever extended (inactive lever during the PR experiment).

$P R$ schedule. Subjects were then moved to a PR3 schedule for 5 days. In this schedule, the first lever press is reinforced, and then the number of presses required to obtain a reward is increased by three after each reinforcement. Finally, mice were tested on PR7 for 3 weeks, 5 days a week. Three different food deprivation conditions were used: $15 \%$ reduction of baseline weight (week 1); $8 \%$ reduction of baseline weight (week 2); and no food deprivation (week 3). Each session terminated after either 45 or $5 \mathrm{~min}$ without response whichever came first. Two parameters were recorded: the breakpoint, defined as the last ratio level completed before mice give up pressing the lever, and number of lever presses on the inactive lever (as a parameter of nonspecific activity).

Concurrent choice task. The concurrent choice task was adapted from the protocol used by Cousins and Salamone (1994) in rats. Under food deprivation (15\% reduction of baseline weight), mice (nine WT and eight DAT KD) were allowed to choose between lever pressing (FR30) for a more preferred food (chocolate flavored $20 \mathrm{mg}$ pellet) or consuming a less preferred standard rodent chow that was concurrently and freely available on the floor of the operant box. Such a schedule (the 'choice' condition) was used on days 1, 3, and 5 of each week; and on days 2 and 4, only the FR30 was available (the 'no choice' condition). Testing lasted for 3 weeks, 5 days per week in a 30 -min session. The number of lever presses, the quantity of lab chow consumed, total amount of food consumed (pellet and rodent chow) and the percentage of food obtained by lever pressing were recorded.

\section{In Situ Hybridization}

A 496-base pair fragment of the mouse Preprodynorphin (Pdyn) cDNA (containing sequence from 120 to 614 nucleotides, GenBank Acc. \# U64968) and a 686-base pair fragment of the mouse Preproenkephalin (PPE) cDNA (containing sequence from 342 to 1025 nucleotides, GenBank Acc. \# M13227) were obtained by PCR and cloned into the $\mathrm{pCR}^{\circledR} 2.1$-TOPO ${ }^{\circledR}$ plasmid (Invitrogen). Antisense cRNA probe were prepared by in vitro transcription from linearized plasmids using ${ }^{33} \mathrm{P}$-labeled UTP (Perkin Elmer) and T7 RNA polymerase, and purified on a BDChroma spin column (BD Biosciences). Cryostat sections $(10 \mu \mathrm{m})$ from six mice per genotype were postfixed in $4 \%$ paraformaldehyde, treated with $20 \mu \mathrm{g} / \mathrm{ml}$ proteinase $\mathrm{K}$, then $2 \mathrm{mg} / \mathrm{ml}$ glycine before a second postfixation in $4 \%$ paraformaldehyde. Following acetylation, the sections were treated in $5 \times$ standard sodium citrate and then prehybridized for $2 \mathrm{~h}$ at $65^{\circ} \mathrm{C}$. The sections were hybridized overnight at $65^{\circ} \mathrm{C}$ with $1.5 \times 10^{6}$ c.p.m. (for Pdyn) and $7.5 \times 10^{5}$ c.p.m. (for PPE) in $200 \mu \mathrm{l}$ of hybridization buffer. After several washes with $0.2 \times$ standard sodium citrate, the slides were exposed on X-ray films (Kodak Biomax) for 2 days. Results were analyzed using NIH ImageJ. Radioactive standards were used to calculate a calibration curve representing the optical density as a function of the radioactivity concentration. 
Measures were taken on three sections across both hemispheres and these counts were averaged to produce a mean.

\section{Immunohistochemistry}

Mice ( $n=6$ per genotype) were anesthetized, and then perfused with $0.9 \% \mathrm{NaCl}$ followed by $4 \%$ paraformaldehyde. Brains were dissected, postfixed in $4 \%$ paraformaldehyde, cryoprotected in $30 \%$ sucrose, and sliced on a microtome into consecutive $50 \mu \mathrm{m}$ sections. Every third sections were used for staining. Slices were incubated for $48 \mathrm{~h}$ at $4^{\circ} \mathrm{C}$ with rabbit anti-mouse FosB antibody (1:500, Santa Cruz). Sections were then incubated for $2 \mathrm{~h}$ at room temperature with biotinylated goat anti-rabbit antibody $(1: 200$, Vector Laboratories) and processed with avidin-biotinylated horseradish peroxidase complex (Elite $\mathrm{ABC}$ kit, Vector Laboratories) for $2 \mathrm{~h}$ at room temperature. The reaction was visualized using diaminobenzidine (DAB, Sigma). Pictures of the regions of interest (dorsomedian and dorsolateral caudate-putamen, core and shell of the nucleus accumbens) were taken with a microscopic CDD camera. Counts of stained nuclei were carried out using the NIH Image. Counts above threshold were taken in a standard frame sample area $(250 \times 350 \mu \mathrm{m}$ for the dorsal caudate-putamen, $150 \times 350 \mu \mathrm{m}$ for the nucleus accumbens) from 3 consecutive sections across both hemispheres and these counts were averaged to produce a mean.

\section{Data Analysis}

Data were analyzed using StatView 5.0.1 independent two-tailed Student's $t$-test was used when genotype was the only grouping variable. ANOVA was used when additional factors were considered. A repeated measure ANOVA was used when data were collected in multiple trials.

\section{RESULTS}

\section{Normal Pavlovian and Operant Learning}

We first tested mice in an autoshaping paradigm in which mice were presented with pairings of a light (CS) and food reward (US). We assessed the acquisition of Pavlovian association between the CS and US with the conditioned response (CR), which was head-poking in the feeder during the CS, prior to the US. All mice acquired the anticipatory head-poking during the $\mathrm{CS}(\mathrm{F}(17,238)=7.59, p<0.001$ for overall trial effect) and there was no genotype difference in the acquisition curve $(\mathrm{F}(17,238)=0.39$, NS for genotype $\times$ trial interaction; Figure 1a). The large standard errors are due to a single DAT KD mouse that started responding on the fifth block with rates that were three to five times higher than any other animal in either group. However, there is no genotype effect with or without this particular subject. We characterized learning speed in the two groups with a method described by Gallistel et al (2004). This procedure recursively examines the data for each subject and detects the points at which responding to the CS exceeds each subject's baseline level of responding. First, we computed an elevation score for each trial by subtracting the rate of responding during the last $12 \mathrm{~s}$ of the ITI from the rate of
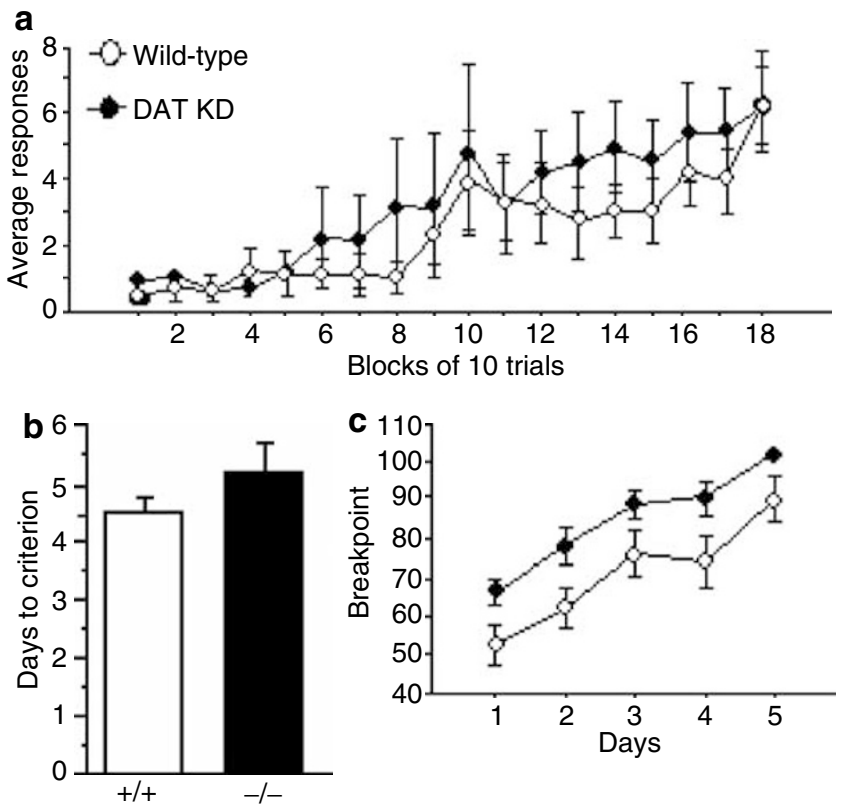

Figure I Normal Pavlovian and instrumental associative learning in DAT KD mice. (a) Both WT and DAT KD mice ( $n=8$ per genotype) developed conditioned responses (anticipatory head-poking) to the conditioned cue (feeder light). Pavlovian learning was indicated by an increase in conditioned responses. There was no genotype difference or difference in learning between genotypes. (b) Acquisition of FRI. Mice from both genotypes ( $n=9$ per genotype) reached the criterion of acquisition (50 lever presses in 45 min on 2 consecutive days) in the same number of days. (c) Mice showed a similar learning curve of the PR3, but DAT KD mice exhibit a higher breakpoint.

responding during the CS. We then created cumulative distributions of elevation scores across trials for each subject. Prior to acquisition, the slope of the cumulative record will be around zero (the rate of responding in the presence and absence of the CS is equal). When acquisition occurs, the cumulative distribution will have a positive slope. The algorithm proceeds datum by datum through the cumulative record looking for a putative change point in the slope. The putative change point is the previous datum that deviates maximally from a straight line drawn from the origin of the plot to the current datum. This putative change point divides the prior data into two samples, those up to and including the putative change point, and those after it. The algorithm then uses the Binomial test to calculate the probability that the observations on the two sides of the putative change point come from the same population. In the current data we use $p<0.000001$ to detect the first positive change point and use this as an estimate of the point of $\mathrm{CR}$ acquisition. Although there is considerable individual variability in learning rates (range from 11 to 132 pairings), there is no significant difference in acquisition rate $(\mathrm{F}(1,14)=0.49$; NS) with the median number of pairings to acquisition being 84 and 82 for the DAT KD and WT mice, respectively.

During instrumental learning, mice were first trained on an FR1 schedule. There was no difference between genotypes in the acquisition of the FR1 (Figure 1b, $t_{16}=-1.34$, NS for overall genotype effect). During acquisition of the PR3 schedule, even though DAT KD 
mice had higher breakpoint throughout the PR3 experiment $(\mathrm{F}(1,64)=5.99, p<0.05$, indicating an higher motivation), both groups acquire the task at the same speed (Figure 1c, $\mathrm{F}(4,64)=0.24$, NS for genotype $\times$ session interaction).

\section{Enhanced PR Performance}

To assess motivation, mice were tested in PR schedules. These schedules, in which the instrumental response requirement to obtain reinforcement is gradually increased throughout the session, measure how hard animals are willing to work for a reward (Hodos, 1961). The strength of motivation is determined by the highest ratio (breakpoint) that the animal can sustain.

During the 3 weeks of PR7 schedule, we tested mice under three food deprivation conditions: 15,8 , and $0 \%$ below baseline body weight. DAT KD mice displayed a higher breakpoint, but only under food deprivation $(\mathrm{F}(1,16)=7.31, \quad p<0.05$ for overall genotype effect; $\mathrm{F}(2,32)=282.39, p<0.0001$ for genotype $\times$ food deprivation condition interaction, Figure $2 \mathrm{a}$ ). In addition, the breakpoint increased with the level of food deprivation in WT mice ( $0 \%$ compared to $8 \%: t_{8}=10.47, p<0.0001 ; 8 \%$ compared to $\left.15 \%: t_{8}=8.44, p<0.0001\right)$; in DAT KD mice, the breakpoint was different between the two lowest levels of deprivation ( $0 \%$ compared to $\left.8 \%: t_{8}=17.04, p<0.0001\right)$, but there was no significant difference in breakpoint at the two higher levels $\left(t_{8}=2.27\right.$, NS).

The pattern of responses on the inactive lever indicated that the increased responses in DAT KD mice were not due
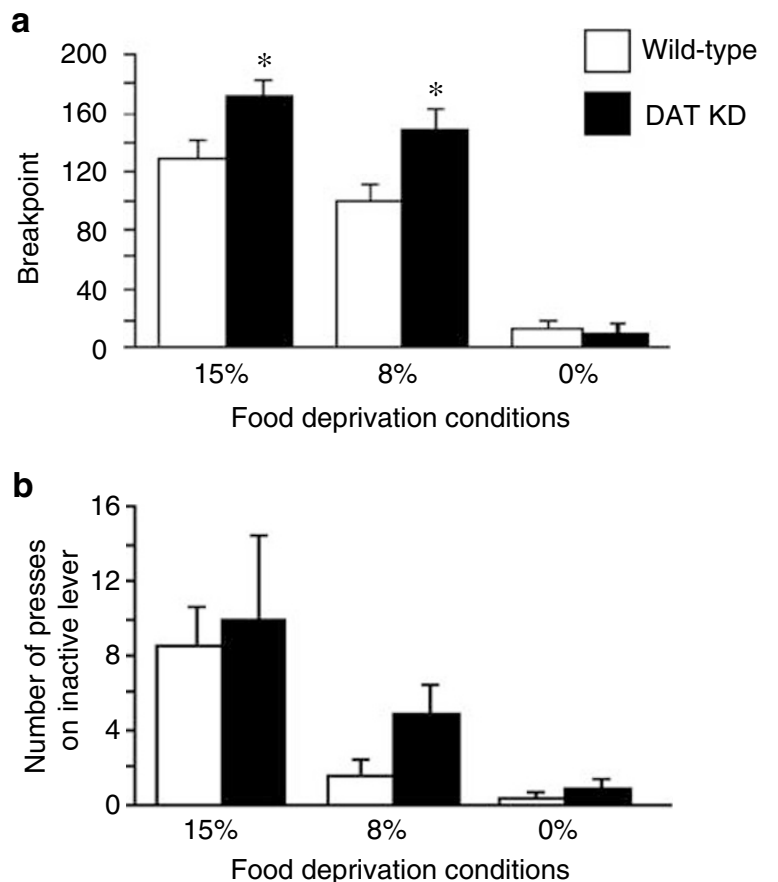

Figure 2 Enhanced motivation in the PR7 schedule. (a) DAT KD mice displayed a higher breakpoint (last ratio completed before giving up lever pressing), but only under the food-deprived condition ( $n=9$ per genotype). (b) The level of nonspecific activity, as measured by the number of presses on the inactive lever, did not differ between the genotypes. $* p<0.05$ to non-specific hyperactivity. Indeed, the number of presses on the inactive lever increased with the level of food deprivation $(\mathrm{F}(2,32)=10.19, p<0.001$; Figure $2 \mathrm{~b})$, but there was no difference between the genotypes $(F(1,16)=0.57$, NS) and no genotype $\times$ food deprivation condition interaction $(\mathrm{F}(2,32)=0.27, \mathrm{NS})$ in this measure of activity.

\section{Enhanced Performance is Specific to Highly Palatable Rewards}

The previous experiment demonstrates that chronically elevated level of dopamine increases the effectiveness of food to motivate goal-directed behavior. We then tested whether this enhancement is to the result of an increase in food appetite or if it is an enhancement of the effort mice are willing to exert to obtain a highly palatable reward.

DAT KD mice lever-pressed more and earned more chocolate flavored pellets in both the 'choice' and 'no choice' conditions $(\mathrm{F}(1,30)=22.50, p<0.0001$ for overall genotype effect; Figure 3a). Interestingly, the genotype difference was much greater under the 'choice' than the 'no choice' condition $(\mathrm{F}(2,60)=5.39, p<0.05$ for genotype $\times$ condition interaction). Moreover, in the 'choice' condition DAT KD mice showed a higher preference than WT controls for lever pressing for the chocolate flavored pellets $(\mathrm{F}(1,15)=8.00, p<0.05$ for overall genotype effect; Figure $3 \mathrm{~d}$ ). There was a tendency for DAT KD mice to eat less rodent chow than WT controls $(\mathrm{F}(1,15)=2.90$, NS for overall genotype effect; Figure $3 \mathrm{~b}$ ). Thus, DAT KD mice showed enhanced motivation for the preferred reward - not an enhanced motivation for food in general. The total quantity of food consumed (rodent chow plus chocolate flavored pellets) was significantly higher in DAT KD mice $(\mathrm{F}(1,15)=4.90, \quad p<0.05$ for overall genotype effect; Figure $3 c)$.

\section{Postsynaptic Adaptations in the Striatum and Nucleus} Accumbens

Projection neurons in the caudate-putamen and nucleus accumbens express peptides whose expression levels are related to specific dopamine receptor activation (Gerfen, 1992; Graybiel, 1995). One population coexpresses the neuropeptide dynorphin and the D1 receptor; the other contains enkephalin and the D2 receptor. Chronic activation of D1 receptors results in upregulation of dynorphin whereas chronic activation of D2 receptors results in downregulation of enkephalin (Gerfen, 1992). We first assessed neuropeptides expression by in situ hybridization (Figure 4a). In DAT KD mice, Pdyn mRNA levels were increased by $140 \%$ in the dorsal caudate-putamen and $40 \%$ in the core of the nucleus accumbens compared to WT controls $\left(t_{10}=-2.26, p<0.05\right.$ for caudate-putamen and $t_{10}=-3.29, p<0.01$ for nucleus accumbens core; Figure $4 \mathrm{~b}$ ) while no change was observed in the shell of the nucleus accumbens $\left(t_{10}=-1.43\right.$, NS, Figure $\left.4 \mathrm{~b}\right)$. In contrast, PPE mRNA levels were not significantly different between genotype in any of the above structures (caudate-putamen: $t_{10}=-0.18$, NS; shell: $t_{10}=-0.16$, NS; core: $t_{10}=-0.35$, NS; Figure 4c).

$\triangle F o s B$ is a member of the Fos family of transcription factors that accumulate in specific brain regions in response 

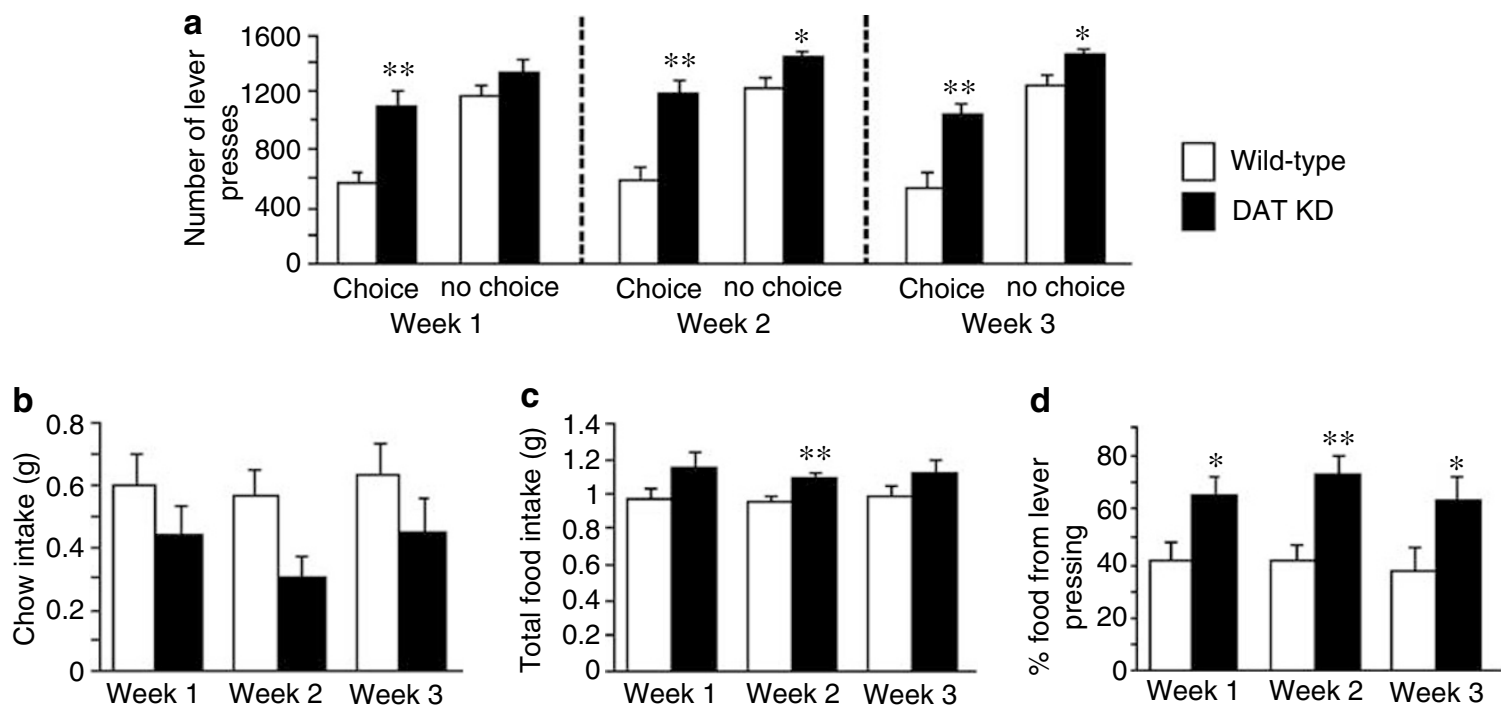

Figure 3 Enhanced motivation in the concurrent choice task. (a) DAT KD mice pressed more and therefore earned more chocolate flavored pellets in both the 'choice' condition and 'no choice' conditions. However, the genotype difference was significantly greater under the 'choice' condition than the 'no choice' condition (9 WT and 8 DAT KD mice). (b) There was no effect of genotype in the quantity of chow consumption (c) The total food intake (pellets and chow) was higher in DAT KD mice. However, this difference was only significant for the second week of testing. (d) The percentage of food obtained from lever pressing during the 'choice' condition was higher in DAT KD mice. $* p<0.05$; $* * * 0.01$.

to chronic stimulation, including repeated administration of drugs of abuse (Nestler et al, 1999). We examined the expression of FosB by immunohistochemistry (Figure 5a). In DAT KD mice, FosB-like immunoreactivity was increased by $30 \%$ in the dorsomedial caudate-putamen (DM CPu, $t_{10}=3.46, p<0.01$; Figure $5 \mathrm{~b}$ ), by $47 \%$ in the dorsolateral caudate-putamen ( $\mathrm{DL} \mathrm{CPu}, t_{10}=2.74, p<0.05$ ), and by $20 \%$ in the core of the nucleus accumbens $\left(t_{10}=3.59, p<0.01\right)$. Again, no difference was observed in the shell of the nucleus accumbens $\left(t_{10}=1.22, \mathrm{NS}\right)$.

\section{DISCUSSION}

The present results demonstrate that the tendency to work, but not the acquisition of Pavlovian and operant responding, for a food reward is enhanced in DAT KD mice with chronically elevated dopaminergic activity, relative to the WT controls. We also found that DAT KD mice displayed increased dynorphin and FosB expression in the dorsal caudate-putamen and the core, but not the shell, of the nucleus accumbens.

\section{Mice with Chronically Elevated Dopamine Exhibit Normal Acquisition of Pavlovian and Operant Responding for a Food Reward}

Disruption of dopamine function by administration of dopamine receptor antagonists impairs Pavlovian conditioning (Di Ciano et al, 2001; Duarte et al, 2003; Parkinson et al, 2002; Spyraki et al, 1982). However, in the current study, both DAT KD and WT mice acquired anticipatory responses to the cue light that was associated with the food at similar rates. Thus, the chronically elevated tonic levels of dopaminergic activity in the DAT KD mice did not affect the acquisition of Pavlovian learning under the current testing conditions.
It is interesting to note that the amplitude of phasic dopaminergic response to electric stimulation was previously found to be reduced in the striatal slices of DAT KD mice compared to that of WT mice (Zhuang et al, 2001). Contrary to the hypothesis predicting that phasic, rather than tonic, releases of dopamine mediate Pavlovian conditioning (Schultz, 2002), this reduction in phasic dopamine did not affect the acquisition of Pavlovian responding in the present study. However, the reduced phasic dopamine release of DAT KD mice may still have been sufficient to allow normal learning. Additionally, the higher motivation displayed by these mice could have compensated for any inherent learning problem. Another possibility is that dopaminergic activity may not be equally altered in all the dopaminergic projections in DAT KD mice and that dopamine activity may be normal in structures important for Pavlovian learning (eg amygdala; Cardinal et al, 2002), leading to normal learning. Indeed, DAT expression level and activity differ depending on the structure and dopamine has been shown to be taken up by the norepinephrine transporter rather than DAT in some brain areas (Carboni et al, 1990; Moron et al, 2002; Yamamoto and Novotney, 1998).

In the current study, DAT KD and WT mice acquired lever pressing for a food reward under the FR1 and PR3 schedules of reinforcement at similar rates. This is consistent with a previous report showing normal operant learning in DAT knockout mice that are also characterized by chronically elevated dopamine levels (Hironaka et al, 2004). Additionally, dopamine-deficient mice, which are unable to synthesize dopamine specifically in dopaminergic neurons (Zhou and Palmiter, 1995), are still capable of instrumental learning (Robinson et al, 2005). This appears to suggest that dopamine is not necessary for operant conditioning. However, in constitutive dopamine mutant mice, counteradaptations during development that oppose the chronic change of dopamine levels could have led to 


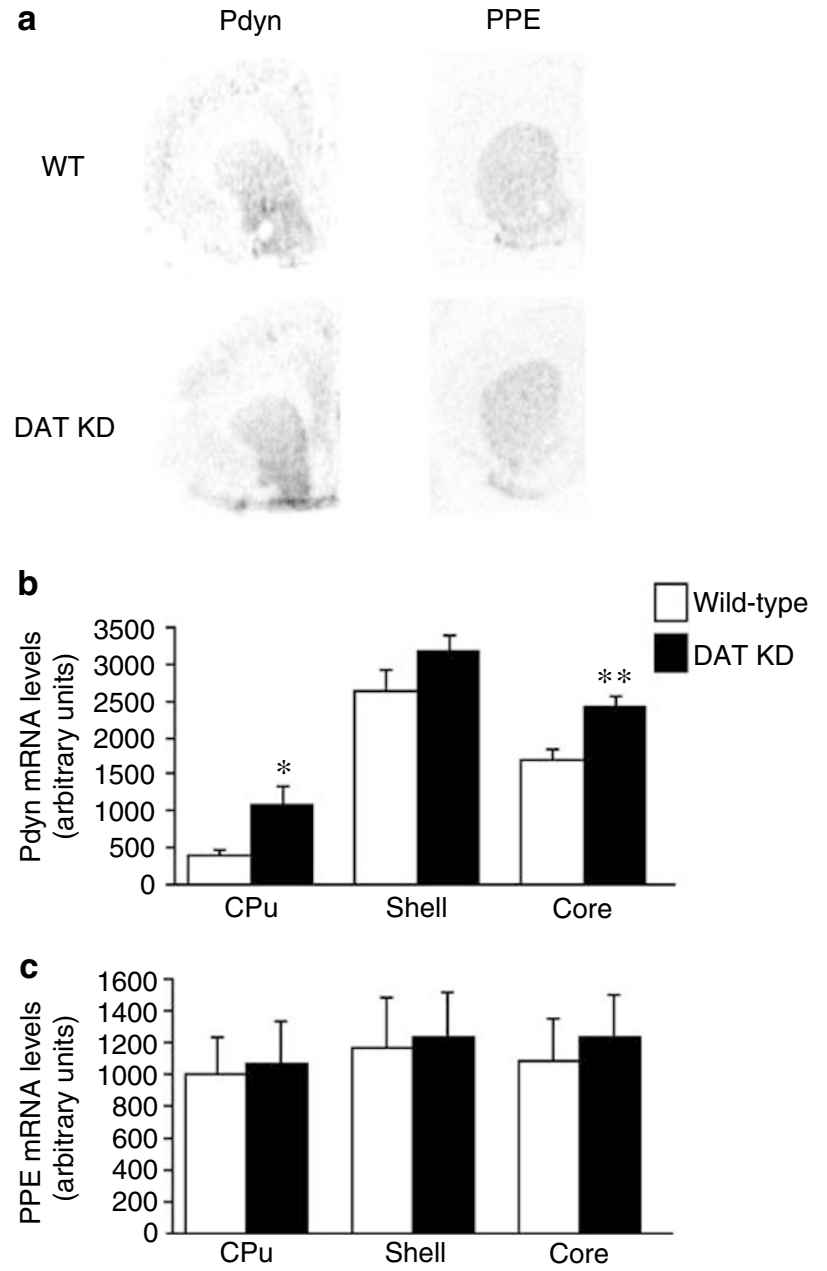

Figure 4 Chronically elevated dopamine tone induced an increase of preprodynorphin (Pdyn) mRNA levels without modifying preproenkephalin (PPE) mRNA levels. (a) Representative pictures of in situ hybridization results using Pdyn and PPE probes in the caudate-putamen (CPu), the shell and the core of the nucleus accumbens ( $n=6$ per genotype). (b) Levels of Pdyn mRNA were higher in the DAT KD mice within the dorsal caudateputamen, the nucleus accumbens core, but not the shell. ${ }^{*} p<0.05$; ${ }_{*}^{*} p<0.0$ l. (c) Quantification of PPE mRNA level showed no genotype difference for any of the structures studied.

normal learning. Indeed, earlier studies using pharmacology as a tool indicated that dopamine receptor antagonists clearly disrupt the acquisition of operant responding in normal animals (Smith-Roe and Kelley, 2000; Wise and Schwartz, 1981). Nonetheless, intra-nucleus accumbens administration of the indirect dopamine agonist amphetamine, which presumably leads to increased local dopaminergic tone, did not affect the acquisition rate of lever pressing for a food reward (Hanlon et al, 2004). Further research is necessary to determine the exact function of dopamine in the acquisition of both Pavlovian and operant responding.

\section{Mice with Chronically Elevated Dopamine Exhibited Enhanced Tendency to Work for a Food Reward}

Dopamine has been extensively demonstrated to modulate the tendency to work for a food reward in a variety of

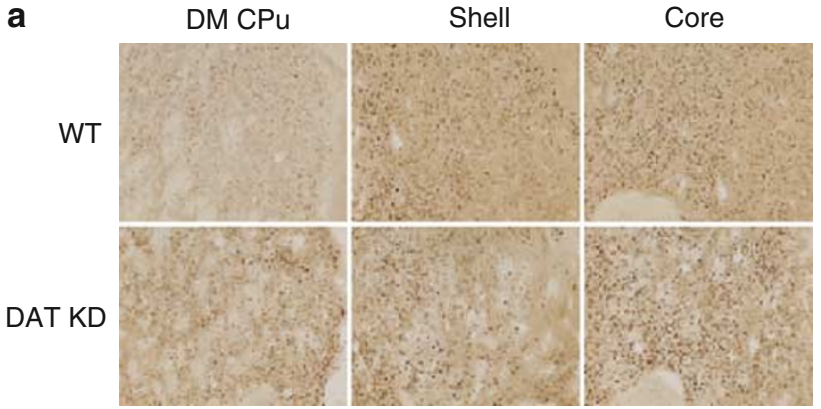

b

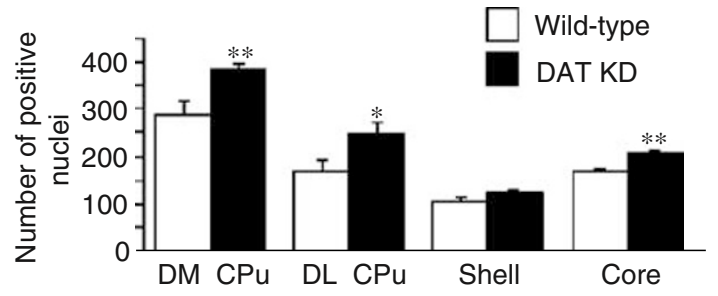

Figure 5 DAT KD mice showed an increase in FosB levels. (a) Representative pictures of FosB immunohistochemical staining in the dorsomedial (DM) and dorsolateral (DL) caudate-putamen (CPu), the shell, and the core of the nucleus accumbens ( $n=6$ per genotype). (b) The numbers of FosB positive nuclei was higher in both the DM and $\mathrm{DL}$ caudate-putamen as well as in the nucleus accumbens core, but not the shell. ${ }^{*} p<0.05$; $* * * 0.01$

paradigms (Aberman and Salamone, 1999; Hamill et al, 1999; Zhang et al, 2003). Interestingly, both phasic and tonic levels of dopaminergic activity have been critically implicated in food-directed behaviors (Kiyatkin, 1995; Schultz et al, 1997). In the current study, DAT KD mice with chronically elevated dopamine level, compared to WT controls, exhibited enhanced performance under the PR schedule as well as a greater tendency to choose more palatable food with a greater work-load requirement under the concurrent choice task. Potential general hyperactivity due to genetic mutation does not seem to account for the different performance displayed by the DAT KD and WT mice. The number of presses on the inactive lever under the PR schedule was identical in both DAT KD and WT mice. Additionally, it is not obvious how an increase in hyperactivity would account for the more extreme preferences of the DAT KD.

DAT KD mice were previously reported to exhibit a greater daily food intake under ad libitum conditions (Pecina et al, 2003). Our results suggest that the chronic elevation in dopaminergic tone may be affecting the motivation to work for a food reward, rather than the general food consumption itself. This interpretation gains additional support from studies that demonstrated that intra-accumbens administration of dopamine antagonists as well as dopamine depletion in the nucleus accumbens did not decrease food intake but induced a shift from lever pressing for a more-preferred food to consumption of a lesspreferred but freely available food (Cousins and Salamone, 1994; Koch et al, 2000; Nowend et al, 2001). Similarly, administration of a dopamine antagonist into the nucleus accumbens reduced the run-speed in a sucrose-reinforced runaway task without affecting the total sucrose consumption (Ikemoto and Panksepp, 1996). Taken together, these 
results indicate that dopamine, particularly in the nucleus accumbens, appears to modulate an animal's tendency to work for food rather than food consumption itself.

Under the non-food-deprived condition, both DAT KD and WT mice worked on the PR schedule and earned the food reward in a similar manner. When tested under fooddeprivated conditions, both genotypes exhibited significantly increased levels of operant responding. This is consistent with previous reports showing that food deprivation increases operant behavior (Eagle et al, 1999) independent of the work requirement to obtain rewards (Aberman and Salamone, 1999). Thus, food deprivation appears to have a general facilitatory effect on operant responding, independent of genotype, reward and work requirements, perhaps mediated by upregulation of D1 and D2 dopamine receptor activity (Carr et al, 2003). However, the magnitude of the food deprivation-induced increase in operant responding was significantly greater in DAT KD than WT mice. Thus, the elevated chronic dopaminergic activity may shift the way in which the external contingency (the PR schedule) and the internal state (food deprivation) of the animal interact to determine responding, so that work output of DAT KD mice increases although the external contingency remains the same.

\section{Mice with Chronically Elevated Dopamine Exhibited Increased Dynorphin and FosB Expressions in the Striatum}

Chronic dopamine stimulation has been reported to upregulate FosB as well as dynorphin and enkephalin expressions (Cole et al, 1995; Gerfen, 1992; Nestler et al, 1999). Consistent with these reports, in the present study, DAT KD mice displayed an increased dynorphin and FosB expression in the dorsal caudate-putamen and the core but not the shell of the nucleus accumbens. However, enkephalin expression was not different in any of the structures studied. Although the antibody we used does not allow us to differentiate the acute from the chronic forms of the FosB family, the chronic form of fos $B$ is induced selectively in dynorphin-containing neurons (Nye et al, 1995) and the FosB pattern of results is similar to the one observed for dynorphin expression, and so may rather reflect a chronic adaptation than an acute effect.

Although it is difficult to determine the exact relationship between the observed molecular and behavioral changes, the present data points out the link between the enhanced striatal FosB and dynorphin expressions to the enhanced tendency to work for a food reward in DAT KD mice. Interestingly, both D1 and D2 receptor antagonists disrupt performance under a PR schedule (Aberman et al, 1998) and the concurrent choice task (Koch et al, 2000), whereas the expression of dynorphin and enkephalin is regulated by D1 and D2 receptors, respectively (Gerfen, 1992). Additionally, FosB and dynorphin have been suggested to underlie long-term behavioral adaptations in response to chronic drug administration (Nestler, 2004). Considering the above, it is plausible that in DAT KD mice, elevated dopaminergic tone lead to the enhanced tendency to work for a food reward as well as the enhanced dynorphin expression through stimulation of D1 receptors.
In the present study, the enhanced FosB and dynorphin expressions were observed both in the caudate-putamen and the nucleus accumbens of the DAT KD mice that also exhibited an enhanced operant performance for a food reward. It is important to note that elevation or depletion of dopamine levels in the nucleus accumbens but not the caudate-putamen has been reported to modulate operant performance under both the PR schedule of reinforcement (Aberman et al, 1998; Zhang et al, 2003) and the concurrent choice procedure (Cousins et al, 1993). Thus, the enhanced operant performance exhibited by DAT KD in the two tasks used in this study is likely mediated by elevated dopamine levels as marked by the enhanced FosB and dynorphin expressions in the nucleus accumbens rather than the caudate-putamen.

Within the nucleus accumbens, both dynorphin and FosB expression levels were enhanced in the core but not the shell of DAT KD mice. Under the concurrent choice task, administration of dopamine antagonist in both the core and the shell was reported to induce a shift from lever pressing to consumption of the freely available food. Although the specific function of nucleus accumbens core $v s$ shell is still a matter of debate (Cardinal et al, 2002), the shell may be important in the response to unconditioned reward and Pavlovian cues, whereas the core may be more important in selection and expression of responses as a function of the value of the reward (Corbit et al, 2001; Di Chiara et al, 2004; Everitt et al, 2001; Ito et al, 2004). In addition, food deprivation not only increases the locomotor activation induced by cocaine or amphetamine, but also induces a greater release of dopamine in the nucleus accumbens core, but not the shell (Cadoni et al, 2003; Carr, 2002). An increased in dopaminergic activity in the nucleus accumbens, in particular the core subdivision, rather than the caudate-putamen may thus explain the enhanced tendency to work exhibited by the DAT KD mice.

\section{ACKNOWLEDGEMENTS}

This work was supported by NIMH Grant MH66216 to XZ, Tourette Syndrome Association Fellowship to BC, NIMH Grant MH068073 to PB and NIDA Grant DA015210 to PB. We thank Dr Kent Berridge for helpful suggestions throughout the experiments and Dr Nobuyoshi Suto for critical reading of the manuscript. Jessica Klein, Lindsay Miller, Diana Park, Mary Shaw and Ali Hussain helped with various aspects of the experiments.

\section{REFERENCES}

Aberman JE, Salamone JD (1999). Nucleus accumbens dopamine depletions make rats more sensitive to high ratio requirements but do not impair primary food reinforcement. Neuroscience 92: 545-552.

Aberman JE, Ward SJ, Salamone JD (1998). Effects of dopamine antagonists and accumbens dopamine depletions on timeconstrained progressive ratio performance. Pharmacol Biochem Behav 61: 341-348.

Beninger RJ, Miller R (1998). Dopamine D1-like receptors and rewardrelated incentive learning. Neurosci Biobehav Rev 22: 335-345. 
Cadoni C, Solinas M, Valentini V, Di Chiara G (2003). Selective psychostimulant sensitization by food restriction: differential changes in accumbens shell and core dopamine. Eur J Neurosci 18: 2326-2334.

Calabresi P, Maj R, Pisani A, Mercuri NB, Bernardi G (1992). Longterm synaptic depression in the striatum: physiological and pharmacological characterization. J Neurosci 12: 4224-4233.

Carboni E, Tanda GL, Frau R, Di Chiara G (1990). Blockade of the noradrenaline carrier increases extracellular dopamine concentrations in the prefrontal cortex: evidence that dopamine is taken up in vivo by noradrenergic terminals. J Neurochem 55: 1067-1070.

Cardinal RN, Parkinson JA, Hall J, Everitt BJ (2002). Emotion and motivation: the role of amygdala, ventral striatum, and prefrontal cortex. Neurosci Biobehav Rev 26: 321-352.

Carr KD (2002). Augmentation of drugs reward by chronic food restriction: behavioral evidence and underlying mechanisms. Physiol Behav 76: 353-364.

Carr KD, Tsimberg Y, Berman Y, Yamamoto N (2003). Evidence of increased dopamine receptor signaling in food-restricted rats. Neuroscience 119: 1157-1167.

Centonze D, Picconi B, Gubellini P, Bernardi G, Calabresi P (2001). Dopaminergic control of synaptic plasticity in the dorsal striatum. Eur J Neurosci 13: 1071-1077.

Cole RL, Konradi C, Douglass J, Hyman SE (1995). Neuronal adaptation to amphetamine and dopamine: molecular mechanisms of prodynorphin gene regulation in rat striatum. Neuron 14: 813-823.

Corbit LH, Muir JL, Balleine BW (2001). The role of the nucleus accumbens in instrumental conditioning: evidence of a functional dissociation between accumbens core and shell. $J$ Neurosci 21: 3251-3260.

Cousins MS, Salamone JD (1994). Nucleus accumbens dopamine depletions in rats affect relative response allocation in a novel cost/benefit procedure. Pharmacol Biochem Behav 49: 86-91.

Cousins MS, Sokolowski JD, Salamone JD (1993). Different effects of nucleus accumbens and ventrolateral striatal dopamine depletions on instrumental response selection in rats. Pharmacol Biochem Behav 46: 943-951.

Cousins MS, Atherton A, Turner L, Salamone JD (1996). Nucleus accumbens dopamine depletions alter relative response allocation in a T-maze cost-benefit task. Behav Brain Res 74: 189-197.

Di Chiara G (2002). Nucleus accumbens shell and core dopamine: differential role in behavior and addiction. Behav Brain Res 137: 75-114.

Di Chiara G, Basareo V, Fenu S, De Luca MA, Spina L, Cadoni C et al (2004). Dopamine and drugs addiction: the nucleus accumbens shell connection. Neuropharmacology 47: 227-241.

Di Ciano P, Cardinal RN, Cowell RA, Little SJ, Everitt BJ (2001). Differential involvement of NMDA, AMPA/Kainate, and dopamine receptors in the nucleus accumbens core in the acquisition and performance of Pavlovian approach behavior. J Neurosci 21: 9471-9477.

Duarte C, Lefebre C, Chaperon F, Hamon M, Thiebot MH (2003). Effects of a dopamine D3 receptor ligand BP897 on acquisition and expression of food-, morphine-, and cocaine-induced conditioned place preference, and food-seeking behavior in rats. Neuropsychopharmacology 28: 1903-1915.

Eagle DM, Humby T, Dunnett SD, Robbins TW (1999). Effects of regional striatal lesions on motor, motivational, and executive aspects of progressive-ratio performance in rats. Behav Neurosci 113: 718-731.

Everitt BJ, Dickinson AD, Robbins TW (2001). The neuropsychological basis of addictive behaviour. Brain Res Rev 36: 129-138.

Gallistel CR, Fairhust S, Balsam PD (2004). The learning curve: Implication of a quantitative analysis. Proc Natl Acad Sci USA 101: 13124-13131.
Gerfen CR (1992). The neostriatal mosaic: multiple levels of compartmental organization. Trends Neurosci 15: 133-139.

Graybiel AM (1995). The basal ganglia. Trends Neurosci 18: 60-62.

Hamill S, Trevitt JT, Nowend KL, Carlson BB, Salamone JD (1999). Nucleus accumbens dopamine depletions and time-constrained progressive ratio performance: effects of different ratio requirements. Pharmacol Biochem Behav 64: 21-27.

Hanlon EC, Baldo BA, Sadeghian K, Kelley AE (2004). Increases in food intake of food-seeking behavior induced by GABAergic, opioid, or dopaminergic stimulation of the nucleus accumbens: is it hunger? Psychopharmacology 172: 241-247.

Hironaka N, Ikeda K, Sora I, Uhl GR, Niki H (2004). Foodreinforced operant behavior in dopamine transporter knockout mice. Ann NY Acad Sci USA 1025: 140-145.

Hodos W (1961). Progressive ratio as a measure of reward strength. Science 134: 943-944.

Hoffman DC, Beninger RJ (1989). The effects of selective dopamine D1 and D2 receptor antagonists on the establishment of agonistinduced place conditioning in rats. Pharmacol Biochem Behav 33: $273-279$.

Ikemoto S, Panksepp J (1996). Dissociations between appetitive and consummatory responses by pharmacological manipulations of reward-relevant brain regions. Behav Neurosci 110: 331-345.

Ito R, Robbins TW, Everitt BJ (2004). Differential control over cocaine-seeking behavior by nucleus accumbens core and shell. Nat Neurosci 7: 389-397.

Kiyatkin EA (1995). Functional significance of mesolimbic dopamine. Neurosci Biobehav Rev 19: 573-598.

Koch M, Schmid A, Schnitzler HU (2000). Role of nucleus accumbens dopamine D1 and D2 receptors in instrumental and Pavlovian paradigms of conditioned reward. Psychopharmacology 152: 67-73.

McCullough LD, Cousins MS, Salamone JD (1993). The role of nucleus accumbens dopamine in responding on a continuous reinforcement operant schedule: a neurochemical and behavioral study. Pharmacol Biochem Behav 46: 581-586.

Moron JA, Brockington A, Wise RA, Rocha BA, Hope BT (2002). Dopamine uptake through the norepinephrine transporter in brains regions with low levels of dopamine transporter: evidence from knock-out mice lines. J Neurosci 22: 389-395.

Nakajima S (1989). Subtypes of dopamine receptors involved in the mechanism of reinforcement. Neurosci Biobehav Rev 13: 123-128.

Nestler EJ (2004). Molecular mechanisms of drug addiction. Neuropharmacology 47: 24-32.

Nestler ER, Kelz MB, Chen J (1999). DeltaFosB: a molecular mediator of long-term neural and behavioral plasticity. Brain Res 835: 10-17.

Nowend KL, Arizzi M, Carlson BB, Salamone JD (2001). D1 and D2 antagonism in the nucleus accumbens core or dorsomedial shell suppresses lever pressing for food but leads to compensatory increases in chow consumption. Pharmacol Biochem Behav 69: 373-382.

Nye HE, Hope BT, Kelz MB, Iadarola M, Nestler EJ (1995). Pharmacological studies of the regulation of chronic FOS-related antigen induction by cocaine in the striatum and nucleus accumbens. J Pharmacol Exp Ther 275: 1671-1680.

Parkinson JA, Dalley JW, Cardinal RN, Bamford A, Fehnert B, Lachenal G et al (2002). Nucleus accumbens dopamine depletion impairs both acquisition and performance of appetitive Pavlovian approach behaviour: implications for mesoaccumbens dopamine function. Behav Brain Res 137: 149-163.

Pecina S, Cagniard B, Berridge KC, Aldridge JW, Zhuang X (2003). Hyperdopaminergic mutant mice have higher 'wanting' but not 'liking' for a sweet rewards. J Neurosci 23: 9395-9402.

Poncelet M, Chermat R, Soubrie P, Simon P (1983). The progressive ratio schedule as a model for studying the 
psychomotor stimulant activity of drugs in the rat. Psychopharmacology 80: 184-189.

Robinson S, Sandstrom SM, Denenberg VH, Palmiter RD (2005). Distinguishing whether dopamine regulates liking, wanting, and/ or learning about rewards. Behav Neurosci 119: 5-15.

Roitman MF, Stuber GD, Phillips PE, Wightman PE, Carelli RM (2004). Dopamine operates as a subsecond modulator of food seeking. J Neurosci 24: 1265-1271.

Salamone JD, Correa M (2002). Motivational views of reinforcement: implications for understanding the behavioral functions of nucleus accumbens dopamine. Behav Brain Res 137: 3-25.

Salamone JD, Cousins MS, Bucher S (1994). Anhedonia or anergia? Effects of haloperidol and nucleus accumbens dopamine depletion on instrumental response selection in a T-maze cost/ benefit procedure. Behav Brain Res 65: 221-229.

Schultz W (2002). Getting formal with dopamine and reward. Neuron 36: 241-263.

Schultz W, Dayan P, Montague PR (1997). A neural substrate of prediction and reward. Science 275: 1593-1599.

Smith-Roe SL, Kelley AE (2000). Coincident activation of NMDA and dopamine D1 receptors within the nucleus accumbens core is required for appetitive instrumental learning. J Neurosci 20: 7737-7742.

Spyraki C, Fibiger HC, Phillips AG (1982). Attenuation by haloperidol of place preference conditioning using food reinforcement. Psychopharmacology 77: 379-382.

Wise RA (2004). Dopamine, learning and motivation. Nat Rev 5: 1-12.

Wise RA, Schwartz HV (1981). Pimozide attenuates acquisition of lever pressing for food in rats. Pharmacol Biochem Behav 15: 655-656.

Yamamoto BK, Novotney S (1998). Regulation of extracellular dopamine by the norepinephrine transporter. J Neurochem 71: 274-280.

Zhang M, Balmadrid C, Kelley AE (2003). Nucleus accumbens opioid, GABAergic, and dopaminergic manipulation of palatable food motivation: contrasting effects revealed by a progressive ratio study in the rat. Behav Neurosci 117: 202-211.

Zhou Q-Y, Palmiter RD (1995). Dopamine-deficient mice are severely hypoactive, adipsic, and aphagic. Cell 83: 1197-1209.

Zhuang X, Oosting RS, Jones SR, Gainetdinov RR, Miller GW, Caron MG et al (2001). Hyperactivity and impaired response habituation in hyperdopaminergic mice. Proc Natl Acad Sci USA 98: 1982-1987. 